\title{
HUBUNGAN ANTARA EFIKASI DIRI DENGAN PROKRASTINASI AKADEMIK PADA SISWA KELAS XI SMAN 1 TONGAUNA
}

\author{
Desriyanti Iskandar ${ }^{1}$, Aspin $^{2}$, Yuliastri Ambar Pambudhi ${ }^{3}$ \\ Program Studi Psikologi \\ Fakultas Keguruan dan Ilmu Pendidikan, Universitas Halu Oleo \\ Email : Desriyantiiskandar@yahoo.com
}

\begin{abstract}
ABSTRAK
Sekolah merupakan tempat untuk menuntut ilmu. Dunia pendidikan khususnya di lingkungan sekolah tugas siswa sangat banyak, terutama tugas terkait mata pelajaran yang mereka pelajari. Tugas yang diberikan pendidik memiliki tujuan, yaitu menyadarkan siswa agar menggunakan waktu luang untuk aktif belajar, dan bertanggung jawab menyelesaikan tugas. Namun dalam pelaksanaannya banyak masalah terkait dengan tugas yang diberikan oleh guru, salah satu masalah yang dihadapi yaitu siswa melakukan penundaan tugas atau prokrastinasi akademik. Ada beberapa penyebab prokrastinasi akademik salah satunya ialah rendahnya efikasi diri yang dimiliki siswa. Oleh karena itu Penelitian ini bertujuan untuk mengetahui hubungan antara efikasi diri dengan prokrastinasi akademik pada siswa kelas XI SMAN 1 Tongauna. Metode yang digunakan dalam penelitian ini adalah kuantitatif korelasional. Pengumpulan data dalam penelitian ini menggunakan skala efikasi diri dan skala prokrastinasi akademik. Responden dalam penelitian ini adalah siswa kelas XI SMAN 1 Tongauna berjumlah 40 orang yang dipilih berdasarkan teknik purposive sampling dari 94 orang. Hasil analisis korelasi Pearson Product moment menunjukkan bahwa terdapat hubungan antara efikasi diri dengan prokrastinasi akademik pada siswa kelas XI SMAN 1 Tongauna $(\mathrm{p}=0,001<0,05)$ dan $r=-0,519$ yang artinya semakin rendah efikasi diri maka akan dibarengi semakin tinggi prokrastinasi akademik.
\end{abstract}

Kata Kunci: Efikasi Diri, Prokrastinasi Akademik.

\section{ABSTRACT}

School is a place to study. In the environment of school education, student assignments are numerous, especially assignments that related to the subjects they have learned. The task given by the teacher has a goal to make students aware for using their free time to actively learn, and to be responsible for completing assignments. But in it's implementation there are many problems related to the assignments given by the teacher, one of the problems is students delay working on their assignments, this habit usually called by academic procrastination. There are several causes of academic procrastination, one of which is the low self-efficacy of students. This research aims to determine the relationship between self-efficacy and academic procrastination in class XI students of SMAN 1 Tongauna. The method used in this research is quantitative correlational. Data collection in this research uses a self-efficacy scale and academic procrastination scale. Respondents in this study were 40 students of class XI of SMAN 1 Tongauna, selected based on purposive sampling techniques from 94 students.The results of the Pearson Product moment correlation analysis show that there is a relationship between self-efficacy and academic procrastination in class XI students of SMAN 1 Tongauna $(p=0.001<0.05)$ and $r=-0.519$ which means the lower the self-efficacy will be accompanied by the higher academic procrastination.

Keywords: Self-Efficacy, Academic Procrastination

\section{Pendahuluan}

Sekolah merupakan tempat untuk belajar seperti membaca, menulis dan berperilaku yang baik. Dunia pendidikan, khususnya di lingkungan sekolah, siswa mendapatkan tugas yang sangat banyak, terutama tugas-tugas terkait mata pelajaran yang mereka pelajari. Tugas- 
tugas yang diberikan kepada siswa memiliki beberapa tujuan, yaitu untuk melatih keterampilan anak dalam memahami, memantapkan konsep-konsep yang telah diajarkan di kelas, menyadarkan siswa selalu menggunakan waktu luang untuk aktif belajar, belajar mandiri, dan bertanggung jawab dalam menyelesaikan tugas.

Cooper \& Valentine, (2001) juga mengatakan, pemberian tugas yang diberikan oleh guru bertujuan agar siswa rajin belajar, mengerjakan tugas dengan baik, mengumpulkan tugas tepat waktu dan siswa dapat membagi waktu antara kegiatan akademik dan non-akademik. Namun dalam praktiknya banyak sekali masalah terkait dengan tugas yang diberikan oleh guru, salah satu masalah yang dihadapi yaitu masih banyak siswa menunda-nunda mengerjakan tugas atau prokrastinasi akademik.

Menurut Ferrari, Johnson, dan Mc Cown (Ghufron \& Risnawita, 2012), prokrastinasi akademik adalah penundaan yang dilakukan secara sengaja, berulangulang dengan melakukan aktivitas di luar dari tugas. Hal ini terjadi disebabkan adanya respon tetap yang bersifat adaptif dan biasanya disertai adanya keyakinankeyakinan irasional yang ada dalam diri individu. Nafeesa (2018) menyatakan bahwa prokrastinasi dapat terjadi pada siapa saja tanpa memandang usia, laki-laki maupun perempuan, dan status sebagai pekerja atau pelajar, tidak ada perbedaan diantaranya. Hasil penelitian yang telah dilakukan sebelumnya oleh Ferrari, dkk (Munawaroh, Alhadi, \& Saputra, 2017) tentang prokrastinasi akademik pada siswa menyebutkan bahwa terdapat $25 \%$ sampai $75 \%$ siswa memiliki masalah prokrastinasi akademik.

Studi pendahuluan yang dilakukan oleh peneliti melalui wawancara dengan guru SMAN 1 Tongauna, memperoleh informasi bahwa kelas yang paling banyak bermasalah dalam melakukan penundaan tugas adalah kelas XI. Pernyataan guru tersebut didukung dengan hasil angket yang dibagikan kepada siswa kelas XI. Hasilnya ditemukan bahwa siswa-siswa di kelas tersebut melakukan prokrastinasi akademik, seperti menunda-nunda mengerjakan tugas dengan sengaja maupun tidak sengaja, menunda untuk menyelesaikan tugas sampai tuntas, dan lebih cenderung memilih melakukan aktivitas lain dari pada mengerjakan tugas.

Peneliti melakukan wawancara kepada siswa berinisial I dan berinisial D. Siswa berinisial I mengatakan dia sering menunda-nunda tugas rumah yang diberikan oleh guru karena dia merasa tugasnya sulit, jadi dia memutuskan untuk tidak mengerjakan tugas tersebut. Sedangkan siswa berinisial D mengatakan dia kurang percaya diri, takut salah dan tidak yakin dengan kemampuannya dalam mengerjakan tugas, sehingga dia menunda-nunda tugas, hingga akhrnya dia tidak mengerjakan tugas.

Selain wawancara di atas peneliti juga mewawancarai beberapa siswa lainnya, dari hasil wawancara Peneliti menemukan penyebab siswa menunda-nunda mengerjakan tugas, yakni : tugas yang diberikan sulit, kelelahan akibat membantu orang tua bekerja, adanya keyakinan diri tidak bisa mengerjakan tugas secara sempurna, perasaan malas, takut salah, adanya kegiatan lain seperti sering bermain handphone, nonton tv, bermain game, dan jalan-jalan. Penyebab di atas didukung dengan beberapa studi terdahulu yang mengungkapkan seseorang melakukan prokrastinasi akademik tidak terjadi dengan sendirinya tetapi disebabkan oleh faktor eksternal dan faktor internal. Faktor eksternal menurut Munawaroh, Alhadi, \& Saputra (2017) yaitu seperti ajakan teman sebaya, kegiatan-kegiatan yang lebih menarik, tidur dan nonton tv (Pychyl, Thiboneau, \& Blunt, 2000). Sedangkan faktor dari internal di antaranya, kelelahan (Rumiani, 2006), kurang percaya diri, memiliki pandangan bahwa suatu tugas 
harus diselesaikan dengan sempurna, takut gagal, dan efikasi diri (Burka, \& Yuen, 2008). Solomon dan Rothblum (1984) juga memaparkan bahwa salah satu faktor yang mendasari individu melakukan prokrastinasi akademik adalah faktor internal yang di antaranya termasuk efikasi diri.

Bandura (1995) mendefinisikan efikasi diri adalah keyakinan individu mengenai kemampuan dirinya dalam melakukan tugas atau tindakan yang diperlukan untuk mencapai hasil tertentu yang diinginkan. Efikasi diri dalam hal ini akan mempengaruhi tindakan siswa ketika menghadapi kendala-kendala dalam mengerjakan tugas sehingga bisa mencapai hasil yang diinginkan. Sehingga siswa yang memiliki efikasi diri yang tinggi akan lebih memungkinkan dirinya untuk tidak menunda-nunda dalam mengerjakan tugas. Sebaliknya apabila siswa memiliki efikasi diri yang rendah maka siswa akan menunda-nunda mengerjakan tugas. Afriyeni \& Murjito (2014) menemukan bahwa efikasi diri dan prokrastinasi memiliki hubungan negatif. Hasil tersebut menjelaskan bahwa siswa yang memiliki efikasi diri rendah atau merasa tidak yakin dengan kamampuannya dalam mengerjakan tugas akan cenderung melakukan prokrastinasi akademik. Sedangkan siswa yang memiliki efikasi diri tinggi atau yakin dengan kemampuannya tidak akan menunda-nunda mengerjakan tugas dan akan mendorong dirinya untuk berusaha mencari solusi pemecahan tugas-tugas. Penelitian lain yang dilakukan oleh Dewi $\&$ Sudiantara (2015) menyatakan hal yang senada bahwa adanya hubungan negatif antara self-efficacy dengan prokrastnasi akademik, artinya semakin tinggi selfefficacy maka semakin rendah prokrastinasi akademik, demikian pula sebaliknya.

Penelitian yang telah dilakukan sebelumnya oleh Afriyeni dan Murjito (2014) serta Dewi dan Sudiantara (2015) terdapat perbedaan dengan skripsi yang peneliti tulis. Perbedaan tersebut meliputi perbedaan pada subjek, tingkat pendidikan subjek, dan tempat penelitian. Pada penelitian ini menggunakan subjek siswasiswi SMAN 1 Tongauna di wilayah Sulawesi Tenggara, sedangkan penelitian sebelumnya menggunakan subjek Mahasiswa dan SMAN 9 Padang di luar wilayah Sulawesi Tenggara.

Berdasarkan fenomena yang telah dikemukakan serta permasalahan yang muncul di kalangan siswa, maka peneliti tertarik melakukan sebuah penelitian yang berjudul "Hubungan Antara Efikasi Diri Dengan Prokrastinasi Akademik Pada Siswa Kelas XI SMAN 1 Tongauna".

Penelitian ini bertujuan untuk mengetahui hubungan antara efikasi diri dengan prokrastinasi akademik pada siswa kelas XI SMAN 1 Tongauna.

Manfaat dalam penelitian ini terbagi menjadi dua yaitu, sebagai berikut:

1. Manfaat teoritis:

Diharapkan dapat memperkaya kajian teori dan riset psikologi.

2. Manfaat praktis:

a. Bagi siswa agar meningkatkan keyakinan dalam mengerjakan tugas

b. Bagi guru agar mengetahui cara menangani siswa, khususnya dalam mengerjakan tugas yang diberikan.

\section{Metode penelitian}

Penelitian ini telah dilakukan di SMAN 1 Tongauna pada tanggal 23-24 September 2019. Jenis penelitian ini adalah penelitian kuantitatif. Desain penelitian yang digunakan adalah korelasional, dengan teknik pengambilan sampel dilakukan dengan teknik purposive sampling. Metode pengumpulan data dalam penelitian ini menggunakan dua skala yaitu skala efikasi diri dan skala prokrastinasi akademik. Skala efikasi diri dalam penelitian ini merupakan modifikasi dari skala yang disusun oleh Oktaviani (2018) yang telah di uji coba 
kepada 116 responden serta memiliki validitas berada pada rentang 0,331-0,784 dan relibilitas 0,942. Skala efikasi diri mengacu pada aspek-aspek efikasi diri menurut Bandura yang terdiri tiga aspek, yaitu level, strength, dan generality. Sedangkan Skala prokrastinasi akademik dalam penelitian ini merupakan modifikasi dari skala yang disusun oleh Kusuma (2010) yang telah di uji coba kepada 110 responden serta memiliki validitas berada pada rentang 0,267-0,706 dan relibilitas 0,931. Skala prokrastinasi akademik mengacu pada ciri-ciri prokrasinasi akademik menurut Ferrari yang terdiri dari empat ciri, yaitu penundaan untuk memulai dan menyelesaikan tugas, keterlambatan dalam mengerjakan tugas, kesenjangan waktu antara rencana serta kinerja aktual, dan melakukan aktivitas yang lebih menyenangkan. sampel penelitian ini adalah siswa kelas XI SMAN 1 Tongauna berjumlah 40 orang yang dipilih berdasarkan teknik purposive sampling dari 94 orang.

Data dalam penelitian ini akan di analisis menggunakan analisis korelasi Pearson Product moment. Analisis korelasi Pearson Product moment adalah uji statistik yang digunakan untuk menguji hipotesis bila kedua uji inferensial terpenuhi yaitu data terdistribusi normal dan linear. Perhitungan analisis dilakukan dengan bantuan program SPSS 21.0 For Windows.

\section{Hasil Penelitian dan Pembahasan Hasil Penelitian}

\section{Uji Validitas}

Berdasarkan uji validitas skala efikasi diri dengan menggunakan bantuan SPSS 21.0 for windows pada setiap item, diketahui bahwa dari 50 item terdapat 20 item (40\%) gugur atau dinyatakan tidak valid sehingga sisa item dinyatakan valid berjumlah 30 item (60\%). Sedangkan, pada skala prokrastinasi akademik berdasarkan uji validitas pada setiap item diketahui bahwa dari 36 item terdapat 10 item (28\%) gugur atau tidak valid sehingga sisa item yang valid berjumlah 26 item (72\%).

2. Uji Reliabilitas

Tabel 1. Hasil uji reliabilitas Skala Cronbach' Alpha

\begin{tabular}{lc}
\hline Efikasi Diri & 832 \\
\hline $\begin{array}{l}\text { Prokrastinasi } \\
\text { Akademik }\end{array}$ & 890 \\
\hline
\end{tabular}

Hasil uji reliabilitas pada kedua skala di atas dapat dikatakan reliabel karena hasil keduanya mendekati rentang angka 1,00 yakni pada skala efikasi diri menunjukkan nilai reliabilitas sebesar 0,832 dan skala prokrastinasi akademik menunjukkan nilai sebesar 0,890, sehingga kedua skala tersebut layak untuk dijadikan sebagai instrumen penelitian yang digunakan untuk mengukur apa yang menjadi variabel penelitian.

3. Uji Asumsi

a. Uji Normalitas

Tabel 2. Hasil uji normalitas

\begin{tabular}{lcc}
\hline \multicolumn{1}{c}{ Variabel } & $\begin{array}{c}\text { Kolmogorov } \\
\text { Smirnov }\end{array}$ & Sig \\
\hline Efikasi Diri & 675 & 0.752 \\
\hline $\begin{array}{l}\text { Prokrastinasi } \\
\text { Akademik }\end{array}$ & 675 & 0.752 \\
\hline
\end{tabular}

Hasil uji normalitas efikasi diri dan prokrastinasi akademik menunjukkan nilai signifikansi sebesar 0,752. Nilai ini lebih besar dari 0,05, hal tersebut menunjukkan bahwa data variabel efikasi diri dan prokrastinasi akademik terdistribusi normal. 
b. Uji Linearitas

Tabel 3. Hasil uji linearitas

\begin{tabular}{cc}
\hline \multicolumn{1}{c}{ Variabel } & $\begin{array}{c}\text { Signifikansi } \\
\text { Deviation from } \\
\text { Linearity }\end{array}$ \\
\hline Efikasi Diri & 0.165 \\
\hline $\begin{array}{l}\text { Prokrastinasi } \\
\text { Akademik }\end{array}$ & 0.165 \\
\hline
\end{tabular}

Hasil uji linearitas menunjukkan nilai signifikansi deviation from linearity sebesar 0,165 . Nilai ini lebih besar dari 0,05, hal tersebut menunjukkan bahwa data variabel efikasi diri dan variabel prokrastinasi akademik dinyatakan memiliki hubungan yang linear.

c. Uji Hipotesis

Tabel 4. Hasil uji korelasi pearson

\begin{tabular}{lcc}
\multicolumn{1}{c}{ product moment } & \\
\hline & $\begin{array}{c}\text { Pearson } \\
\text { Correlation }\end{array}$ & Sig \\
\hline Efikasi Diri & -0.519 & 0.001 \\
\hline $\begin{array}{l}\text { Prokrastinasi } \\
\text { Akademik }\end{array}$ & -0.519 & 0.001 \\
\hline
\end{tabular}

Hasil analisis data diperoleh angka koefisien korelasi sebesar 0,519, dengan nilai signifikansi sebesar 0,001, maka ada hubungan negatif yang signifikan antara efikasi diri dengan prokrastinasi akademik pada siswa kelas XI SMAN 1 Tongauna.

Sugiyono (2014) membagi kekuatan hubungan menjadi beberapa tingkatan, sebagai berikut:
Tabel 5. Tingkat hubungan variabel

Interval koefisien Tingkat Hubungan

\begin{tabular}{ll}
\hline $0,00-0,199$ & Sangat Rendah \\
\hline $0,20-0,399$ & Rendah \\
\hline $0,40-0,599$ & Sedang \\
\hline $0,60-0,799$ & Kuat \\
\hline $0,80-1,000$ & Sangat kuat \\
\hline
\end{tabular}

Penelitian ini masuk dalam kategori sedang, karena hasil analisis data diperoleh angka koefisien korelasi sebesar -0,519.

\section{Pembahasan}

Penelitian ini dilakukan dengan tujuan untuk mengetahui hubungan antara efikasi diri dengan prokrastinasi akademik pada siswa kelas XI SMAN 1 Tongauna. Sampel Penelitian ini menggunakan 40 orang. Hasil dari penelitian diperoleh angka koefisien -519 , hal tersebut menunjukan ada hubungan yang signifikan antara kedua variabel.

Hasil penelitian ini didukung oleh beberapa penelitian, diantaranya adalah penelitian yang dilakukan oleh Afriyeni \& Murjito (2014) pada 66 orang responden dimana hasil penelitiannya yang menyatakan bahwa ada hubungan negatif antara efikasi diri dan prokrastinasi akademik. Siswa yang memiliki efikasi diri rendah atau merasa tidak yakin dengan kemampuannya dalam mengerjakan tugas akan cenderung melakukan prokrastinasi akademik. Sedangkan siswa yang memiliki efikasi diri tinggi atau yakin dengan kemampuannya tidak akan menundanunda mengerjakan tugas dan akan mendorong dirinya untuk berusaha mencari solusi pemecahan tugas-tugas. Selain itu, penelitian ini senada pula dengan penelitian yang dilakukan oleh Dewi dan Sudiantara (2015) tentang hubungan self-efficacy dengan prokrastinasi akademik pada mahasiswa psikologi kurikulum berbasis kompotensi Universitas Katolik Soegijapranata 
Semarang yang menyatakan bahwa terdapat hubungan yang negatif yang signifikan antara self-efficacy dengan prokrastinasi akademik. Dengan meningkatkan self-efficacy maka perilaku prokrastinasi akademik akan menurun.

Jika dipandang berdasarkan pada data yang dihasilkan dilapangan bahwa 40 siswa kelas XI SMAN 1 Tongauna cenderung melakukan prokrastinasi akademik, seperti menunda-nunda mengerjakan tugas, menunda untuk menyelesaikan tugas sampai tuntas jika mereka sudah mulai mengerjakan tugas, sengaja tidak segera mengerjakan tugas dan sering melakukan aktivitas lain daripada mengerjakan tugas. Data yang diperoleh sesuai dengan teori yang dikemukakan oleh Ferrari, Johnson, dan Mc Cown (Ghufron \& Risnawita, 2012) ciri-ciri prokrastinasi akademik yaitu penundaan untuk memulai dan menyelesaikan tugas, keterlambatan dalam mengerjakan tugas, kesenjangan waktu antara rencana serta kinerja aktual, dan melakukan aktivitas yang lebih menyenangkan.

Solomon dan Rothblum (1984), menyatakan faktor dalam diri yang mendasari individu melakukan prokrastinasi akademik yaitu efikasi diri. Bandura (1995) mendefinisikan efikasi diri adalah keyakinan individu mengenai kemampuan dirinya dalam melakukan tugas atau tindakan yang diperlukan untuk mencapai hasil tertentu yang diinginkan. Efikasi diri dalam hal ini akan mempengaruhi tindakan siswa ketika menghadapi kendala-kendala dalam mengerjakan tugas, hal ini berarti siswa yang sedang mengerjakan tugas akan bersumber pada efikasi diri. Siswa yang memiliki efikasi diri yang rendah maka lebih mungkin akan menunda-nunda mengerjakan tugas. Hal tersebut juga terlihat pada siswa kelas XI SMAN 1 Tonguna yang memiliki efikasi diri rendah, ketika siswa mendapatkan tugas siswa suka menunda-nunda mengerjakan tugas karena siswa tidak yakin dengan kemampuannya, merasa kurang sempurna dalam mengerjakan tugas, dan adapun siswa menyelesaikan tugas yang diberikan dengan bantuan dari temannya karena siswa tersebut merasa tidak yakin dengan kemampuan diri sendiri dalam mengerjakan tugas. Sedangkan siswa yang memiliki efikasi diri yang tinggi akan lebih memungkinkan dirinya untuk tidak menunda-nunda dalam mengerjakan tugas, karena siswa yang memiliki efikasi diri tinggi akan mendorong dirinya untuk berusaha mencari solusi pemecahan tugas-tugas dan bertindak dalam mengerjakan tugas.

\section{Kesimpulan dan Saran Kesimpulan}

Berdasarkan hasil penelitian yang dilakukan pada siswa kelas XI SMAN 1 Tongauna tentang hubungan antara efikasi diri dengan prokrastinasi akademik, didapatkan hasil yaitu terdapat hubungan negatif yang signifikan antara efikasi diri dengan prokrastinasi akademik pada siswa kelas XI SMAN 1 Tongauna yang ditunjukan dengan angka koefisien korelasi sebesar -0,519. Artinya bahwa semakin tinggi efikasi diri maka akan dibarengi dengan semakin rendahnya prokrastinasi akademik, sebaliknya semakin rendah efikasi diri maka akan dibarengi dengan semakin tinggi pula prokrastinasi akademik pada siswa kelas XI SMAN 1 Tongauna.

\section{Saran}

1. Bagi Siswa

Diharapkan bagi siswa kelas XI SMAN 1 Tongauna agar dapat lebih meningkatkan efikasi diri yang dimiliki dengan cara memahami setiap saran dan nasihat yang diberikan oleh guru atau teman ketika menghadapi tugas yang sulit. Ketika saran dan nasihat telah dipahami maka siswa akan berpikir dan berusaha memperbaiki dalam proses mengerjakan atau menyelesaikan tugas, sehingga siswa mampu 
mengatasi kendala-kendala dalam mengerjakan tugas dan diharapkan siswa lebih meningkatkan kemampuan dalam mengatur waktu penyelesaian tugas.

2. Bagi Guru dan Sekolah

a. Diharapkan bagi guru SMAN 1 Tongauna agar memberikan dorongan motivasi, dan nasihat kepada siswanya untuk percaya bahwa mereka mampu sukses dengan kemampuan yang dimilikinya.

b. Diharapkan bagi guru SMAN 1 Tongauna agar memberikan bimbingan kelompok agar meningkatkan efikasi diri siswa.

3. Bagi Peneliti Selanjutnya

a. Setelah peneliti mencari tahu hubungan efikasi diri dengan prokrastinasi akademik, diharapkan peneliti selanjutnya agar mencari tahu bagaimana pengaruh efikasi diri terhadap prokrastinasi akademik.

b. Diharapkan peneliti selanjutnya mencari tahu perbedaan prokrastinasi akademik antara perempuan dan laki-laki. Atau menggunakan variabel lain yang belum diungkap dalam penelitian ini.

\section{Daftar Pustaka}

Afriyeni, N., \& Murjito, W. H. (2014). Hubungan antara Efikasi Diri dengan Prokrastinasi Akademik pada Siswa Kelas XI Sekolah Menengah Atas Negeri 9 Padang. Jurnal Antropologi, 16 (2). Doi:1025077.

Bandura, A. (1995). Self-Efficacy in Changing Societies. New York: Cambridge University Press.

Burka, J. B., \& Yuen, L. M. (2008). Procrastination: Why You Do It, What to Do About It Now.
Amerika: Cambridge Da Capo Press.

Cooper, H., \& Valentine, J. C. (2001). Using Research to Answer Pratical Questions About Homework. Journal Educational Psychologist, 36, 143-153.

Dewi, N. P.,\& Sudiantara, Y. (2015). Hubungan Self Efficacy dengan Prokrastinasi Akademik pada Mahasiswa Fakultas Psikologi Kurikulum Berbasis Kompetensi Universitas Katolik Soegijapranata Semarang. Jurnal Psikodimensia, 14 (2), 96-104. Doi:1024167.

Ghufron, M. N. \& Risnawita, R. (2012). Teori-Teori Psikologi (cetakan ke3). Yogyakarta: Ar-Ruzz Media.

Kusuma, L. W. A. (2010). Kecenderungan Perilaku Prokrastinasi Akademik pada Mahasiswa Psikologi.Yogyakarta:Fakultas Psikologi USD.

Munawaroh, M. L., Alhadi, S., \& Saputra. W. N. E. (2017). Tingkat Prokrastinasi Akademik Siswa Sekolah Menengah Pertama Muhammadiyah 9 Yogyakarta. Jurnal Kajian Bimbingan dan Konseling, 2 (1), 26-31. Doi:1017977.

Nafeesa. (2018). Faktor-Faktor yang Mempengaruhi Prokrastinasi Akademik Siswa yang Menjadi Anggota Organisasi Siswa Intra Sekolah. Jurnal Antropologi Sosial dan Budaya, 4 (1), 53-67. Doi:1024114.

Oktaviani, M. P. (2018). Tingkat Efikasi Diri Dalam Belajar Siswa SMK.Yogyakarta:Fakultas Keguruan dan Ilmu Pendidikan USD. 
Pychyl, T. A., Thiboneau, R., \& Blunt, A. (2000). Five Days Of Emotion: An Experience Sampling Study og Undergraduate Student Procrastination, Journal of Behavior and Personality, 15, 239254.

Rumiani. (2006). Prokrastinasi Akademik Ditinjau dari Motivasi Berprestasi dan Stres Mahasiswa. Jurnal Psikologi Universitas Diponegoro, 3 (2), 37-48. Doi:1014710.

Solomon, LJ.,\& Rothblum, E.D. (1984). Academic Procrastination:

Frequency andCognitive Behavioral Correlates. Journal of Counseling Psychology, 31 (4).

Sugiyono. (2014). Metode Penelitian Kuantitatif Kualitatif dan $R \& D$. Bandung: Alfabeta. 